\title{
Psychometric properties of the indicators of professional competence for exercise instructors for elderly people
}

\author{
Chih Ping Li ${ }^{1}{ }^{\dagger}$, Hsiao Ching Lan ${ }^{2}$
}

\begin{abstract}
Physical exercise and activity may prevent cognitive decline and neurodegenerative diseases, and promise mastery experience, self-persuasion, and diminution in negative sentimental states in elderly people. This study was to examine the validity of the indicators of professional competence for exercise instructors of the elderly (IPCEIE). We have reported to use the Delphi technique and the analytic hierarchy process (AHP) to develop the IPCEIE with 72item (IPCEIE-72) (three second-orders: knowledge, skill, and attitude). However, to date there has been no study of the validity of psychiatry IPCEIE. A convenience sample of 145 exercise instructors ( $46.36 \pm 14.64)$ was self-administered data from structural questionnaire. The total score of the three dimensions reflect the overall IPCEIE status (i.e., third-order factor). However, factor structures of the IPCEIE have not been examined. Therefore, the main purpose of this study was to examine 10-factor first-order models, 3-dimentions second-order models, and one third-order model of the IPCEIE using confirmatory factor analysis (CFA). We also examined 83-item of the original IPCEIE (IPCEIE-83) to compare with the IPCEIE-72.The IPCEIE-72 showed an unaccepted model $\left(X^{2} / d f=6.516, C F I=0.92, N N F I=0.91\right.$, and $\left.\mathrm{RMSEA}=0.196\right)$ and all 72 items had sufficient factor loadings (0.59-0.86). Comparing to the original IPCEIE, the IPCEIE-83 also resulted a good model fit $\left(X^{2} / d f=5.462, C F I=0.93, N N F I=0.92\right.$, and $\left.R M S E A=0.176\right)$ and all 83 items had sufficient factor loadings (0.59-0.85). In summary, both the IPCEIE-72 and IPCEIE-83 had satisfactory construct validity in the one third-order model of the IPCEIE, but there did not converge in 3-dimentions second-order models of the IPCEIE-72. Therefore, we suggested that future users may use the IPCEIE- 83 to capture the multiple dimensions of IPCEIE with management skill items although some exercise experts did not think there are needed.
\end{abstract}

\section{Keywords}

IPCEIE, Confirmatory factor analysis, Elderly people

\section{Introduction}

Physical health has an important effect on both objective and subjective quality in late life [1]. Previous studies and current evidence show, physical health in terms of chronic illnesses, functioning, disability, sensory impairment, alcohol abuse, frailty, and falls are absent from elderly people who may experience a better quality of life. In contrast, elderly people with worse physical health may have a poor quality of life or live short [2]. Therefore, improving and maintaining physical health, may play a major role in maintaining quality of life in old age. Exercise is one of methods to keep and maintain physical health for elderly people. For example, physical exercise and activity may elevate peripheral brain-derived neurotrophic factor (BDNF) in healthy humans by acute and chronic aerobic exercise [3] and prevent cognitive decline and neurodegenerative diseases in elderly people through nonpharmaceutical

'Department of Health Industry Management, Kainan University, Taoyuan city, Taiwan

${ }^{2}$ Department of Tourism and Hospitality Management, Kainan University, Taoyuan city, Taiwan

${ }^{\dagger}$ Author for correspondence: Chih Ping Li, Assistant Professor at the Department of Health Industry Management, Kainan University, Luzhu District, Taoyuan 33857, Taiwan. Tel: +886 (3) 341-2500 ext. 7974; Fax: +886 (3) 270-5906, email: lichihping@hotmail.com 
intervention [4]. Coelho and colleagues (2014) used a controlled design to explore the effects on BDNF levels of elderly people with Alzheimer's disease by acute aerobic and they found that aerobic exercise increases BDNF plasma levels for Alzheimer's and healthy elderly people. They suggested BDNF levels had association with level of physical activity [5]. Burzynska and colleagues (2014) explored the relationship between physical activity, cardiorespiratory fitness and neural correlates in later life and they found that health elderly people participate in physical activity are important in maintaining white matter [6]. On the other hand, physical exercise and activity promise mastery experience, self-persuasion, and diminution in negative sentimental states [7]. However, some barriers limit to engage in exercise for elderly people, for example, they do not have friends, place, poor athletic skills, lack of motivation [8], lack of information and understanding, lack of guidance and communication, general misunderstanding related to exercise, even do not know proper physical fitness etc $[9,10]$. All of these factors may result in being decreasingly interest to participate in exercise, disengage in sociology, and lead to lonely life $[11,12]$.

The concepts of the indicators of professional competence for exercise instructors of the elderly (IPCEIE) are practical as a guiding principle for exercise instructors to using in exercising class among elderly people [13]. The IPCEIE enables exercise instructors to improve their knowledge, attitude, management, plan, and ability to coping with elderly people in exercise class. On the other hand, elderly people also could obtain the benefit from the exercise instructors, such as increase of self-assurance, physical health, social participant, and quality of life.

The IPCEIE is an instrument designed to convey a standard in multidimensional constructs. The original development of the IPCEIE was based on the elderly people exercise from several researchers $[13,14]$. They suggested that exercise instructors should with ten professional competences when they conduct exercise for elderly people. Followed by this study, they developed the IPCEIE by using Grounded Theory and confirmed the professional competency of exercise instructors for the elderly that contains five factors which are professional knowledge, professional skill, professional attitude, personality traits, and communication skills [14].
Furthermore, the IPCEIE was produced 83item (first-order), 11-factor (second-order), and 3-factor (third-order) as Table 1. Later than using the Delphi technique and the analytic hierarchy process (AHP) [15], researchers identified 3 third-order factors (professional knowledge, professional skills, and professional attitude), 10 second-order factors (teaching attitude, exercise knowledge, professional growth, exercise safety, personal characteristics, exercise instructor, gerontology knowledge, communicative competence, curriculum design, and motor skill), and 72 first-order items. However, to our knowledge, no researches have yet examined the factor dimensions (i.e., first-, second-, third-order models) of both the IPCEIE-83 and the IPCEIE-72. Therefore, the aim of this research was to assess the construct validity of the IPCEIE-83 and the IPCEIE-7.

\section{Methods \\ - Participants and Ethics}

The IPCEIE was developed using qualitative methods, however, no studies have evaluated the construct validity using CFA. Therefore, this research used a convenience sampling strategy to recruit participants in northern Taiwan from September 2014 to May 2015. We visited various northern Taiwan urban districts that had established elderly exercise classes (Health Village, the Tai Chi Chuan Association, and the Elder Academy) and collected data from eligible exercise instructors via the self-administered questionnaire. Eligible participants needed to meet the following criteria by (1) being an exercise instructor of elderly people with more than 2-years' experience, (2) having at least an elementary level of education, and (3) being of an age of at least 25 but no more than 70 years. The total of 204 participants met the inclusion criterion and agreed to complete the questionnaire. Upon reviewing the participants' answers, we found that we could only accept 145 (71\%) as the remainder had not been filled out completely.

This research was approved by the Research Ethics Committee of National Taiwan University (NTU-REC No.: 201407ES013). Participants obtained informed consent and the participants' records/information were anonymized and de-identified prior to analysis in this research. In keeping with the Personal Information Protection Act of Taiwan, the personal data collected will continue be kept confidential and 
Research Chih Ping Li

\begin{tabular}{|c|c|c|c|}
\hline Third-order & Second-order & First-order & Note* \\
\hline \multicolumn{4}{|l|}{ Knowledge } \\
\hline & \multicolumn{2}{|c|}{ Gerontological knowledge } & \\
\hline & & 1. Elderly physiology & \\
\hline & & 2. Elderly psychology & \\
\hline & & 3. Elderly sociology & deleted \\
\hline & & 4. Elderly nutrition & \\
\hline & & 5. Physical activity and aging & \\
\hline & & 6. Common diseases in elderly & \\
\hline & & 7. Successful aging & \\
\hline & & 8. Benefit policy in aging & deleted \\
\hline & & 9. Health maintenance in aging & \\
\hline & Exercise knowl & & \\
\hline & & 10. Sport pedagogy & \\
\hline & & 11. Sport psychology & \\
\hline & & 12. Sports anatomy & \\
\hline & & 13. Sport coaching methods & \\
\hline & & 14. Physical fitness & \\
\hline & & 15. Protection from Exercise Injury & \\
\hline & & 16. Exercise management & deleted \\
\hline & & 17. Exercise physiology & \\
\hline & & 18. Sports mechanics & \\
\hline \multicolumn{4}{|c|}{ Professional Skill } \\
\hline & \multicolumn{2}{|c|}{ Curriculum design } & \\
\hline & & 19. Arranging curriculum systematically & \\
\hline & & 20. Design curriculum innovation & \\
\hline & & 21. Design elderly physical activity curriculum & \\
\hline & & 22. Design teaching media & deleted \\
\hline & & 23. Design exercise for elderly with chronic diseases & \\
\hline & & 24. Design exercise fitness for elderly & \\
\hline & & 25. Design exercise of preventing fall for elderly & \\
\hline & & 26. Design goals for each exercise steps & \\
\hline & \multicolumn{2}{|l|}{ Exercise skill } & \\
\hline & & 27. Knowing well exercise kinematics for elderly & \\
\hline & & 28. Knowing well exercise action skills for elderly & \\
\hline & & 29. Knowing well exercise action technology for elderly & \\
\hline & & 30. Knowing well sport equipment's and use & \\
\hline & \multicolumn{2}{|l|}{ Exercise safety } & \\
\hline & & 31. Doing Physical examination for elderly & \\
\hline & & 32. Evaluating exercise ability of elderly & \\
\hline & & 33. Preventing sport injure & \\
\hline & & 34. Dealing sport injure & \\
\hline & & 35. Doing CPR & \\
\hline & & 36. Evaluating safety of exercise environment & \\
\hline & \multicolumn{2}{|c|}{ Exercise guidance } & \\
\hline & & 37. Explaining exercise goals clearly & \\
\hline & & 38. Explaining exercise skill & \\
\hline & & 39. Demonstrating standard action & \\
\hline & & 40. Speaking clearly instruction & \\
\hline & & 41. Creating good atmosphere for learning & \\
\hline & & 42. Evaluating physical fitness efficiency & \\
\hline & & 43. Providing different exercise guidance methods & \\
\hline & \multicolumn{2}{|c|}{ Management skill } & deleted \\
\hline & & 44. Having recruiting members ability & deleted \\
\hline & & 45. Maintaining sport equipment's ability & deleted \\
\hline & & 46. Having marking ability & deleted \\
\hline
\end{tabular}


Psychometric properties of the indicators of professional competence for exercise instructors for elderly people

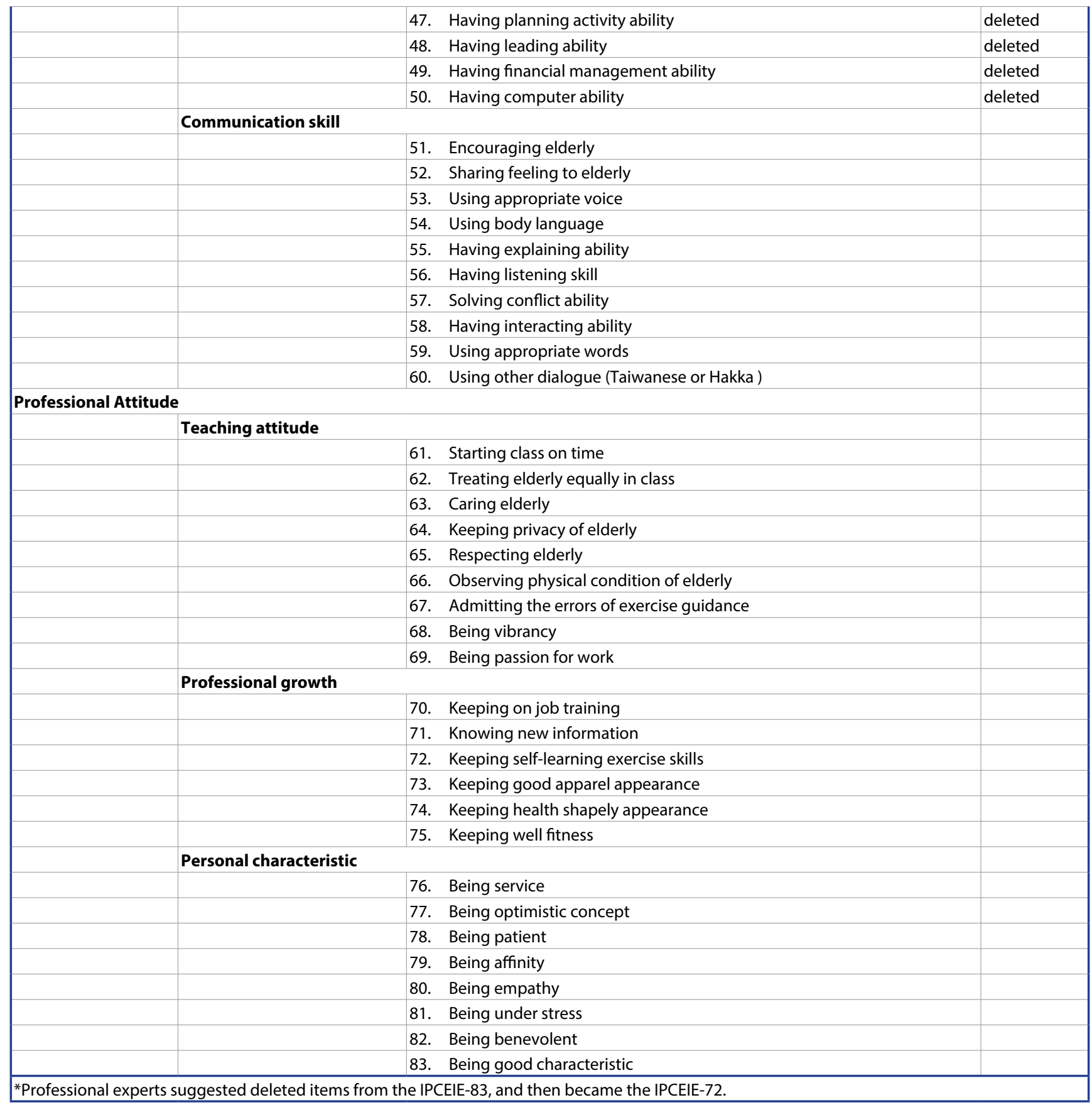

secure until its destruction upon the publication of this research.

\section{Instruments and data analyses}

The IPCEIE was created in accordance with the previous literature, the Grounded Theory and the Delphi technique $[14,15]$. The original IPCEIE included 83 items (11-factor), followed by the professional group's opinions changed to 72 items (10-factor). We examined validity of the IPCEIE-83 and the IPCEIE-72 with a fivepoint Likert-type scale ( $1=$ Strongly Disagree,
2=Disagree, 3=Uncertain, 4=Agree, 5=Strongly Agree). First, we examined the first-order factor dimensions (i.e., 11-factor model) of the IPCEIE. After that the 3 second-factor models were assessed if the 11 second-factor was supported. Following the 3 second-factor models resulted in acceptable; the third-order model was examined.

Data were recorded on SPSS for Windows version 18.0 to do descriptive analyses [16] and internal consistency (Cronbach's alpha) [17]. The LISREL 8.8 software [18] was used to examine confirmatory factor analysis (CFA) 
with goodness-of-fit indices for validating the one dimensional construct of items. This research used criterion that included the relative chi-square criterion $\left(\chi^{2} / d f \leq 5.0\right) \quad[19,20]$, comparative fit index $(\mathrm{CFI} \geqq 0.9)[21,22]$, non-normed fit index (NNFI $\geqq 0.9)$ [19], and the root mean square error of approximation (RMSEA $\leqq 0.05$ ) [23]. RMSEA $\leqq 0.05$ with an upper limit of the 90 percentage confidence interval between 0.100 and 0.15 was reflected on an acceptable model fit [24].

\section{Results}

A total of 145 participants $(46.36 \pm 14.64)$ met the criteria of this research, $52.4 \%$ were male, $38.6 \%$ had university level education, and more information showed in Table 2 . The total reliability of the IPCEIE-83 was 0.979 and 3 -factor reliability was that gerontological knowledge was 0.932 , professional skill was 0.968 , and professional attitude was 0.959 . Cronbach's $\alpha$ of the 11 factors were from 0.857 to 0.948 (Table 3).

The IPCEIE with 72-item showed an unaccepted model $\left(\chi^{2} / d f=6.516, \mathrm{CFI}=0.92, \mathrm{NNFI}=0.91\right.$, and RMSEA $=0.196$ ) and all 72 items had sufficient factor loadings (0.59-0.86). However, some first-order and second-order models did not converge, although third-order model had an accepted model $(\chi 2 / \mathrm{df}=3.61, \mathrm{CFI}=0.96$, $\mathrm{NNFI}=0.94$, and RMSEA $=0.14$ ).

The IPCEIE with 83-itemresulted an unaccepted model $(\chi 2 / \mathrm{df}=5.46, \mathrm{CFI}=0.93, \mathrm{NNFI}=0.92$, and

\begin{tabular}{|c|c|c|c|c|}
\hline Characteristic & $\mathbf{N}$ & $\%$ & Mean & SD \\
\hline Age & 145 & & 46.36 & 14.64 \\
\hline \multicolumn{5}{|l|}{ Gender } \\
\hline Female & 69 & 47.6 & & \\
\hline Male & 76 & 52.4 & & \\
\hline \multicolumn{5}{|l|}{ Education } \\
\hline Elementary school & 2 & 1.4 & & \\
\hline Junior high school & 25 & 17.2 & & \\
\hline Senior high school & 16 & 11.0 & & \\
\hline College & 12 & 8.3 & & \\
\hline University & 56 & 38.6 & & \\
\hline Master & 30 & 20.7 & & \\
\hline $\mathrm{PhD}$ & 4 & 2.8 & & \\
\hline \multicolumn{5}{|c|}{ Teaching recreational sport } \\
\hline Tai chi chuan & 43 & 29.7 & & \\
\hline Wai dan chuan & 38 & 26.2 & & \\
\hline Yang sheng exercise & 15 & 10.3 & & \\
\hline Fitness exercise & 22 & 15.2 & & \\
\hline Others & 27 & 18.6 & & \\
\hline
\end{tabular}

\begin{tabular}{|c|c|c|c|}
\hline Dimension & First-order & Second-order & Third-order \\
\hline The IPCEIE & & & 0.979 \\
\hline Knowledge & & 0.932 & \\
\hline Gerontological knowledge & 0.900 & & \\
\hline Exercise knowledge & 0.901 & & \\
\hline Skill & & 0.968 & \\
\hline Curriculum design & 0.857 & & \\
\hline Exercise skill & 0.917 & & \\
\hline Exercise safety & 0.908 & & \\
\hline Exercise guidance & 0.905 & & \\
\hline Management skill & 0.916 & & \\
\hline Communication skill & 0.920 & & \\
\hline Attitude & & 0.959 & \\
\hline Teaching attitude & 0.924 & & \\
\hline Professional growth & 0.896 & & \\
\hline Personal characteristic & 0.948 & & \\
\hline
\end{tabular}


Psychometric properties of the indicators of professional competence for exercise instructors for elderly people

Research

\begin{tabular}{|c|c|c|c|c|c|}
\hline Index & $\begin{array}{c}\text { First-order CFA } \\
\text { with 72-item }\end{array}$ & $\begin{array}{l}\text { Gerontology knowledge } \\
\text { subscale (2-order) }\end{array}$ & $\begin{array}{c}\text { Professional skill subscale } \\
\text { (2-order) }\end{array}$ & $\begin{array}{l}\text { Professional attitude } \\
\text { subscale (2-order) }\end{array}$ & $\begin{array}{c}\text { The IPCEIE-72 } \\
\text { (3-order) }\end{array}$ \\
\hline$x^{2}$ & 228.07 & The model did & The model did & The model did & 115.60 \\
\hline$d f$ & 35 & not converge. & not converge. & not converge. & 32 \\
\hline $\mathrm{X}^{2} / d f$ & 6.516 & & & & 3.613 \\
\hline $\mathrm{CFI}$ & 0.92 & & & & 0.96 \\
\hline NNFI & 0.91 & & & & 0.94 \\
\hline RMSEA & 0.196 & & & & 0.135 \\
\hline Index & $\begin{array}{l}\text { First-order CFA } \\
\text { with 83-item }\end{array}$ & $\begin{array}{l}\text { Gerontology knowledge } \\
\text { subscale (2-order) }\end{array}$ & $\begin{array}{l}\text { Professional skill subscale } \\
\text { (2-order) }\end{array}$ & $\begin{array}{l}\text { Professional attitude } \\
\text { subscale (2-order) }\end{array}$ & $\begin{array}{l}\text { The IPCEIE-83 } \\
\text { (3-order) }\end{array}$ \\
\hline$x^{2}$ & 240.34 & The model was & 6.74 & The model was & 130.56 \\
\hline$d f$ & 44 & saturated, the fit & 6 & saturated, the fit & 41 \\
\hline$x^{2} / d f$ & 5.462 & was perfect. & 1.348 & was perfect. & 3.184 \\
\hline CFI & 0.93 & & 1.00 & & 0.96 \\
\hline NNFI & 0.92 & & 0.99 & & 0.95 \\
\hline RMSEA & 0.176 & & 0.049 & & 0.123 \\
\hline
\end{tabular}

RMSEA=0.18) and all 83 items had sufficient factor loadings (0.59-0.85); however, first-order, second-order, and third-order $(\chi 2 / \mathrm{df}=3.18$, $\mathrm{CFI}=0.96, \quad \mathrm{NNFI}=0.95$, and $\mathrm{RMSEA}=0.12$ ) models met the criteria and were a good fit of this research sample as illustrated in Table 4.

\section{Discussion}

This research is the first study to employ CFA determines the factor structures of the IPCEIE in exercise instructors. We examined the IPCEIE-72 and the IPCEIE-83 models (i.e., first-order, second-order, and third-order) to determine their robust for advance application and validation. First, we examined both the models of the IPCEIE both with 72-item and with 83-item; however, these two models presented insufficient models. Although CFI and NNFI showed a good fit, but the relative chi-square criterion and RMSEA did not meet criteria. Finally, both the IPCEIE-72 and the IPCEIE-83 in third-order had accepted models, and the IPCEIE-83 presented a better model than the IPCEIE-72 because the IPCEIE- 83 has 11 more items of support.

We then examined the three second-order subscales of the IPCEIE-72 and found that they did not converge. In our previous paper, a group of 11 professional exercise experts suggested the deletion of items such as 'Elderly sociology', 'Benefit policy in aging', 'Exercise management', 'Design teaching media', 'Having recruiting members ability', 'Maintaining sport equipment function', 'Having marketing ability', 'Having planning activity ability', 'Having leadership ability', 'Having financial management ability', and 'Having computer skills'. After 11 items were deleted, the IPCEIE-83 became IPCEIE-72. However, we considered that these items regarding management skill in organizing elderly people for exercise physical and leisure activities to be important. Finally, the results confirmed our thinking and most exercise instructors agreed that these items were very important in their work. Alternatively, three second-order subscales of the IPCEIE-83 had very good support in these models. These results suggested that the 11 items should not be deleted, especially the 'elderly sociology' item. These findings confirmed our view that exercise benefits not only physical health but it also promotes social relationships and mood improvement for elderly people [12].

Third-order models of both the IPCEIE-72 and the IPCEIE-83 then were shown to have a good model-fit. The IPCEIE- 83 model was better than the IPCEIE-72 model because the IPCEIE-72 lacked one second-order factor (Management skill). This result showed that most exercise instructors supported the management skill factor in this scale. This also supported our assumption that elderly people need to be guided, lead, and managed in group exercise to prevent physical performance loss, and social isolation [9].

One limitation of this research is that maximum likelihood (ML) failed to converge to secondorder models in the IPCEIE-72 because of the small sample size. The ML might have difficulty converging under some of the sample conditions selected because the lower rates of non-convergence for this method resulted in a smaller sample size. The ratio of sample size is 5 to 1 for free parameters [25]. Although this research did not meet this goal, lower sample sizes can be used in the following 3 conditions: 
(1) models with no latent variables, (2) all loadings are fixed (usually to one), and (3) with simpler models [25]. A second limitation of this research is the homogeneity of the population in exercise instructors. Further researchers might find different results if they use a heterogeneous population for example: fitness trainers, developers with community-based elderly groups, etc.

\section{Conclusion}

In summary, both the IPCEIE-72 and IPCEIE-83 had satisfactory construct validity in the one third-order model, but they did not converge in 3-dimentional second-order models of the IPCEIE-72. Therefore, we suggest that further users (i.e. exercise instructors, fitness trainers, and program developers in communities or senior centers, case managers, social workers in long-term care facilities) use the IPCEIE-83 to capture the multiple dimensions of IPCEIE with management skill items although we acknowledge that a few of the exercise experts did not agree they were needed.

\section{Conflict of Interest}

The authors declare that there is no conflict of interest regarding the publication of this paper.

\section{Funding Statement}

$N / A$

\section{References}

1. Li CP. Quality of Life Patterns and Survival Among Older People. J. Nursing. Res 21(2), 94-109 (2013).

2. Li CP. Life Satisfaction as a Predictor of Mortality Hazard Among Elderly People in the United Kingdom and Taiwan. J. Nursing. Res 21(1):26-38 ( 2013).

3. Huang $T$, Larsen $\mathrm{K}$, Ried-Larsen $\mathrm{M}$, et al. The effects of physical activity and exercise on brain-derived neurotrophic factor in healthy humans: A review. Scand. J. Med. Sci. Sports 24(1), 1-10 (2014).

4. Bherer L, Erickson KI, Liu-Ambrose T. A Review of the Effects of Physical Activity and Exercise on Cognitive and Brain Functions in Older Adults. J. Aging. Res 2013(1), 8 (2013).

5. Coelho FGdM, Vital TM, Stein AM, et al. Acute aerobic exercise increases brain-derived neurotrophic factor levels in elderly with Alzheimer's disease. J. Alzheimers. Dis 39(2), 401-408 (2014).

6. Burzynska AZ, Chaddock-Heyman L, Voss $M W$, et al. Physical activity and cardiorespiratory fitness are beneficial for white matter in low-fit older adults. PloS. one 9(9), e107413 (2014).

7. Warner LM, Schüz B, Wolff JK, et al. Sources of self-efficacy for physical activity. Health. Psy 33(11), 1298-1308 (2014).

8. Manaf H. Barriers to participation in physical activity and exercise among mid- dle-aged and elderly individuals. Singapore. Med. J 54(10), 581-586 (2013).

9. Moschny A, Platen P, Klaaßen-Mielke R, et al. Barriers to physical activity in older adults in Germany: a cross-sectional study. Int. J. Behav. Nutr. Phys. Act 8(1), 1-10 (2011).

10. Horne $M$, Tierney $S$. What are the barriers and facilitators to exercise and physical activity uptake and adherence among South Asian older adults: a systematic review of qualitative studies. Prev. Med 55(4), 276-284 (2012).

11. Black DS, Irwin MR, Olmstead R, et al. Tai chi meditation effects on nuclear factor-KB signaling in lonely older adults: a randomized controlled trial. Psychother. Psychosom 83(5), 315-317 (2014)

12. Diamond A. Effects of physical exercise on executive functions: going beyond simply moving to moving with thought. Ann. Sports. Med. Res 2(1), 1011 (2015).

13. Lan HC, Yang TW. The professional competence for exercise instructors of the elderly. Sports. Exercise. Res 104(1), 16-22 (2009).

14. Zheng HW, Lu JH, Lan HC. Professional Competency of Exercise Instructors for the Elderly: A Grounded Theory Approach. $D a$ Zhuan Ti Yu Xue Shu Zhuan Kan 330-337 (2010).

15. Lan HC, Li CP, Zheng HW. The construction of the indicators of professional competence for exercise instructors of the elderly. Technol. Health. Care 24(s1), S325-S335 (2016).
16. SPSS Inc. PASW Statistics for Windows, Version 18.0. Chicago, IL: SPSS Inc. (2009).

17. Cronbach L. Coefficient alpha and the internal structure of tests. Psychometrika 16(3), 297-334 (1951).

18. Sörbom D, Jöreskog K. LISREL 8.8 for Windows. Chicago, IL: Scientific Software International (2006).

19. Bollen KA. A New Incremental Fit Index for General Structural Equation Models. Sociol. Methods. Res 17(3), 303-316 (1989).

20. Schumacker RE, Lomax RG. A beginner's guide to structural equation modeling, Second edn. Mahwah, NJ: Lawrence Wrlbaum Associates (2004).

21. Bentler PM. Comparative fit indexes in structural models. Psychol. Bull 107(2), 238246 (1990).

22. Bentler PM, Bonett DG. Significance Tests and Goodness of Fit in the Analysis of Covariance Structures. Psychol. Bull 88(3), 588-606 (1980).

23. Browne MW, Cudeck R. Alternative Ways of Assessing Model Fit. Sociol. Methods. Res 21(2), 230-258 (1992).

24. Hooper D, Coughlan J, Mullen M. Structural equation modelling: Guidelines for determining model fit. J. Res. Natl. Inst. Stand. Technol 6(1), 53-60 (2008).

25. Bentler PM, Chou C. Practical issues in structuralmodeling. Soc. Meth. Res 16(1), 78-117 (1987) 